\title{
应用化学一流本科专业建设的探索与实践 以北京化工大学为例
}

杨屹 ${ }^{*}$, 陈咏梅, 许家喜, 白守礼, 刘建军, 孙艳芝, 鄢红, 陆军, 冯拥军, 王涛, 何静

北京化工大学化学学院, 北京 100029

摘要: “双一流” 建设的根本任务是一流人才培养, 一流专业是一流人才培养的基本单元。本文以北京化工大学应 用化学专业为例, 从培养目标定位, 深化专业综合改革措施, 师资队伍和质量保障体系建设等方面介绍了一流专业 建设的思路、举措及成效。并提出了持续改进的方向，以期为相关专业建设提供借鉴。

关键词: 应用化学; 一流专业建设; 理工融合

中图分类号: G64; O6

\section{Exploration and Practice on the Construction of First-Class Applied Chemistry Major: Taking Beijing University of Chemical and Technology as an Example}

Yi Yang ", Yongmei Chen, Jiaxi Xu, Shouli Bai, Jianjun Liu, Yanzhi Sun, Hong Yan, Jun Lu, Yongjun Feng, Tao Wang, Jing He

College of Chemistry, Beijing University of Chemical Technology, Beijing 100029, China.

Abstract: The basic task of "Double First-class" construction is the cultivation of first-class talents. First-class major is the basic unit. Taking the applied chemistry major of Beijing University of Chemical Technology as an example, the ideas, measures and results of cultivation objective orientation, comprehensive reform, teachers team and quality assurance system construction were described. The direction of continuous improvement was proposed. This paper may provide some references for constructing first-class chemistry-related or other majors.

Key Words: Applied chemistry; First-class major construction; Science and engineering integration

高等学校的根本任务是人才培养，一流本科、一流专业、一流人才，是高等教育强国的根和本， 一流专业是一流人才培养的基本单元 ${ }^{[1]}$ 。如何结合国家的需求及学校的特色, 建设一流专业、培养 一流人才, 是高等学校持续探索的时代命题。北京化工大学是新中国为 “培养尖端科学技术所需求 的高级化工人才” 而创建的一所高水平大学, 经过 60 余年的建设, 已经发展成为理科基础坚实, 工 科实力雄厚, 富有特色的多科性重点大学, 化学工程与技术(含应用化学)是国家重点学科, 化学学科 是国家 “ “985” 优势学科创新平台” 和 “211工程” 重点建设的学科之一, 在ESI全球排名中保持前 $1 \% 0$ 行列。“绿色化学化工及材料” 学科群 2017 年列入一流学科建设之列。学校建校以来为国家输送

收稿: 2020-08-31; 录用: 2020-11-12; 网络发表: 2020-12-11

“通讯作者, Email: yangyi@mail.buct.edu.cn

基金资助: 北京化工大学 2018 年本科教育教学改革研究项目(2018BHDJGP10) 
了一大批化学化工领域科技人才, 为我国经济建设做出了卓越的贡献。

我校应用化学本科专业始建于1986年，1992年改办精细化工专业和工业分析专业，1999年恢复 应用化学专业, 授理学学士学位。在学校 “大化工” 背景下, 我校面向学科发展和区域经济发展需 求, 全面落实立德树人根本任务, 以建设世界一流本科应用化学专业, 培养推动科学发展、实现企 业成为创新主体所需要的高素质创新人才为目标, 对人才培养模式进行持续改革与实践, 形成了 “理

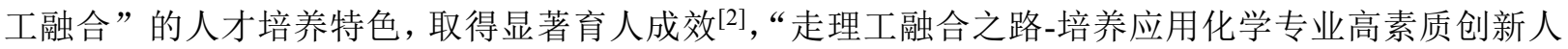
才” 等4项教学成果先后获国家级优秀教学成果二等奖, 2019年应用化学专业入选首批教育部 “双万 计划”国家级一流本科专业建设点。

\section{1 构建强化理工基础、突出化学应用的培养方案和课程体系}

应用化学是以化学理论为基础、多学科交叉、跨领域应用的最有活力的学科之一, 在化工、材 料、能源、信息、环境等与国民经济密切相关的领域占有重要地位。我校应用化学专业旨在培养能 够进行化学基础研究和应用研究、科技开发和科技管理的理工融合型创新人才。针对人才培养目 标, 构建了数理化理论基础、工程能力培养、专业特色以及创新创业教育并重的应用化学专业人才 培养方案。

以国家级化学基础课程优秀教学团队为依托, 加强化学基础, 无机化学、分析化学、有机化学、 物理化学、结构化学课程全部选用国内经典理科教材或国际经典教材的中译本, 强化课程的深度。 同时辅以国际经典的原文教材作为辅助教材, 开阔学生的国际视野。以国家工科基础课程物理教学 基地和数学建模基地为依托, 加强数理基础, 高等数学(11学分)、线性代数(3学分)、概率论与数理 统计(3学分)全部为必修课程, 普通物理及大学物理实验课程也均选择高学分课程 $(8+2$ 学分)。强调 数学物理基础在化学专业课中的应用四年不断线, 培养科学思维能力和运用数理基础知识解决化学 化工中实际问题的能力。以化工原理、机械工程和电工电子 3 个北京市实验教学示范中心为依托, 开 设化工原理、化工制图、应用电工学、电工电子实习等工科课程, 奠定工程能力基础。强化计算机 基础及应用, 开设 C语言程序设计、应用软件实习等课程。突出理工基础融合, 开设数学、化学与计 算机科学多学科交叉的计算化学特色课程。

基于国家发展需求及学科特色, 依托化工资源有效利用国家重点实验室、新危险化学品评估及 事故鉴定基础研究实验室、环境有害化学物质分析北京市重点实验室、北京市多级结构催化材料工 程技术中心等科研机构, 设置了分析科学与技术、功能材料、有机合成三个专业特色方向。创建了 一批专业特色课程, 例如复杂物质剖析、分析测试质量保证、商品检验基础、应用电化学、催化化 学、产品工程学、表面活性剂与界面化学、精细化工工艺学等, 同时开设了纳米技术与生物医药、 电化学应用技术构创与研发等高年级研讨课程, 突出化学的应用性。

设置创新创业模块课程, 将创新创业课程及创新创业活动纳入学分体系, 鼓励学生积极参与科 学研究与创新创业实践活动。学生可以通过参加本科生导师制、参加校内外学术会议、参加各类学 科竞赛和大学生创新创业训练计划、发表论文、申请专利、科技获奖、职业认证及自主创业等, 获 得相应的创新学分。

\section{2 深化专业综合改革, 全方位提升育人质量 \\ 2.1 以更新观念为先导, 推进课程改革与创新}

课程是专业建设的核心要素, 是高校立德树人的重要载体。课程支撑着人才培养目标的达成, 直 接影响着人才培养的质量。学生从大学里受益的最直接、最核心、最显效的是课程 ${ }^{[3]}$ 。课程带给学生 的不仅仅是知识的获得, 还有能力的训练和素质的养成。我们秉承 “以教为主” 向 “以学为主” 转 变, 从 “课堂为主” 向 “课内外结合” 转变, 从 “结果评价为主” 向 “结果和过程评价相结合” 转 变的教育教学理念, 建设化学系列课程。 
(1) 充分发挥课堂主渠道在学校思想政治工作中的作用。

以有机化学、物理化学两门校级本科课程思政示范课为引领, 在基础课和专业基础课程中全面 开展课程思政建设, 使化学课程与思想政治理论课同向同行, 将知识传授与价值引领贯穿教育教学 全过程。例如, 无机化学课程中, 通过介绍 “侯氏制碱法” 与 “索尔维制碱法” 的相同点和不同点, 了解侯德榜先生的创新、务实、爱国精神。在有机化学课程教学过程中, 通过介绍中国科学家在艰 苦的条件中, 集体攻关, 首次完成了从有机小分子氨基酸到生物大分子胰岛素的合成, 体现了我国 老一代科学家团结、拼搏、艰苦奋斗、敢想敢干的科学精神。物理化学教学中将马克思主义认识论 贯穿物理化学始终。仪器分析课程介绍中国第一个火星探测器 “天问一号” 中搭载的分析仪器, 提 升民族自信。分离科学与技术课程结合新冠病毒核酸检测, 使学生认识科学对人类的贡献以及我国 医务工作者敬业奉献精神。

(2) 积极推进信息技术与教育教学的融合。

建设了物理化学、有机化学、仪器分析、计算化学、复杂物质剖析、大学化学实验等6门国家精 品课程, 2013年全部升级为国家精品资源共享课程。2018年起, 建设了物理化学、有机化学、仪器 分析、计算化学、复杂物质剖析、中级有机化学、有机化学分子建模、结构化学、大学化学实验等 9门在线开放课程, 已在中国大学MOOC平台上线, 其中仪器分析、物理化学、有机化学、计算化学 4门课程被评为首批国家级一流本科课程。同时出版了《物理化学数字课程》《仪器分析数字课程》

《计算化学数字课程》《中级有机化学数字课程》等数字课程教材 4 部。依托所建立的课程资源, 在 北京市教学改革项目 “面向大化工类专业的仪器分析课程案例库建设的研究与实践”、校级教改项目 “ “有机合成” 研究型教学示范课程”、“新工科背景下 ‘无机合成” 课程内容及教学模式的改革研究 与实践” 等项目的支持下, 开展翻转课堂及混合式教学、案例教学、研究型教学等, 增强课程教学 的互动性、探究性和个性化, 培养学生的自主学习能力。

(3) 构筑多元化课程考核评价体系。

发挥学校在线教育综合平台及 “雨课堂” 等工具的作用, 对课前-课上-课后进行全链条学习过程 管理, 强化过程考核, 将出勤率、课堂互动表现、课堂小测验、作业情况、在线教育综合平台预习 及答疑讨论情况、小论文情况等纳入平时成绩, 与期中期末考试一并构成全过程考评体系, 更加全 面地评价学生的学习效果。

\section{2 以产学研一体化为依托, 培养创新实践能力}

依托化学化工国家级实验教学示范中心、各级重点实验室及实习基地构建了 “化学基础实验-专 业实验-认识实习、生产实习-专业实践-毕业论文” 课内实践教学体系, 与第二课堂相结合, 形成了 螺旋式上升、四年不断线的多层次、多元化的自主创新能力培养体系。

(1) 基础实验和专业实验中实施 “基础实验-综合实验-研究性实验”三层次实验教学, 在注重基 本实验技能训练的基础上, 将开放式、设计式实验教学模式引入教学过程。综合实验、专业实验的 大部分内容由教师的科研项目转化而来, 使学生尽早了解科技前沿, 培养分析和解决问题能力以及 创新意识。

(2) 以校企合作共赢思路建设实习基地, 搭建校企协同创新平台。教师为企业解决技术难题, 企 业为学生开设实习课堂, 设立奖教金, 学校为企业开辟校园招聘绿色通道, 实现企业、教师、学生 多赢。近年来, 建设了中石化燕山分公司、国家体育总局兴奋剂检测中心、山东晨吴化工有限公司、 北京海岸鸿蒙标准物质技术有限公司、北京赛林泰医药技术有限公司等 10 余个校外实习基地, 初步 实现按专业方向进行的 “精准” 认识实习和生产实习。

(3) 创建丰富的第二课堂。开展各类学科竞赛, 包括数学竞赛、数学建模竞赛、物理竞赛、化学 实验竞赛等。由我校化学化工国家级实验教学示范中心承办的北京市大学生化学实验竞赛多年来开 展 “创新实验设计” 的竞赛活动, 鼓励学生依据基本实验原理和基本实验技能解决生产、生活和科 学研究中的问题。由我校发起的 “北京高校联合纸桥承重大赛” 成为北京市二十余所高校、七千余 
名学生参加的大型竞赛活动, 得到中国教育电视台、《中国科学报》等多家媒体的关注。依托各级科 研平台, 开展科研训练计划, 包括萌芽杯、大学生科技创新计划、挑战杯以及导师制科研实验室体 验等。近三年学生共参加大学生创新创业计划141项, 在各类竞赛中获奖672人次。

\section{3 以 “普遍成才、追求卓越” 为宗旨, 实施分层次个性化培养}

采取 “单独招生, 小班教学, 未位淘汰、择优进入” 的机制, 设立 “优培班”, 旨在为对化学具 有强烈兴趣, 并立志在化学研究领域有所成就的学生提供一个独特的学习平台。“优培班” 低年级采 用小班教学模式, 课程设置强调化学基础, 由学校最优秀的师资为该班授课, 化学基础课程采取双 语教学, 同时开设与国际接轨的前沿课程及全英文研讨课等。入选的学生在本科学习阶段, 利用前 三年的时间修完主要的化学基础和专业课程, 在本科四年级进入高水平科研团队开展本科毕业论文 训练, 并可以选修硕士 / 博士阶段的课程。培养过程中名师授课、专家讲座、导师制、科研训练计 划等全员覆盖, 人才培养效果显著。2019年毕业的首届优培班学生有 $87 \%$ 在国内外高校或研究所继 续深造，2020年毕业的优培班深造率高达 $91 \%$ 以。

\section{4 以 “学科交叉” 为平台, 探索人才培养新模式}

当今科学发展越来越呈现出多学科交叉的特点, 学科交叉不仅成为创新思想的源泉, 更是大学 创新文化的一个基本内核。我校从2013年起启动了 “学科交叉人才培养计划”, 培养学生的跨学科交 叉能力, 为学生在相关领域的 “个性化” 发展提供平台。化学学院依托化工资源有效利用国家重点 实验室, 由院士、长江学者和杰出青年基金获得者领衔, 组建 “超分子科学” “层状材料与资源能源” 和 “插层催化” 3 个 “学科交叉班”, 从大二、大三本科生中选拔优秀学生进入交叉班, 以应用化学 专业学生为主体, 同时招收化学工程学院和材料学院相关专业学生, 最大程度保证交叉班组成学生 的跨学科学缘结构。学生在教师指导小组的指导下, 进行跨专业选课, 参加团队组会、研讨课、学 术交流和科研课题研究等学术活动。经过交叉班培育的学生在大学生创新计划及学院组织的科研活 动中均有良好表现, 会以另一个学科的视角审视原有学科的问题, 提出自己的见解, 直至找到解决 问题的新方法、新技术。参加学科交叉班的学生保研率大于 $50 \%$, 还有一部分学生选择考研或出国 深造。2010级栗振华同学作为学校2013年首批 “学科交叉班” 成员之一, 是我校创新教育体制培养 出来的优秀学生代表, 在段雪院士和杰出青年基金获得者卫敏教授的指导下, 围绕 “插层结构材料 与电化学能源存储/转换” 取得系列具有国际影响力的研究成果, 以第一/共一作者在Angew. Chem.,

Chem, Adv. Mater, Nano Energy, Chem. Sci. 等国际权威化学材料类期刊发表论文14篇, 荣获博士生 校长奖学金、唐敖庆化学奖学金, 两次获得研究生国家奖学金。目前已在北京化工大学任教, 晋升 为副教授。

\section{5 以培养国际化人才为目标, 构筑国际化拓展平台}

在全球竞争的高科技时代, 使学生具备国际化的视野和国际化竞争力, 具有较强的跨文化沟通 能力, 是大学教育的重要目标。为实现这一目标, 构筑了由双语教学体系、111引智创新基地、欧洲 和北美联合培养基地组成的国际化拓展平台。

开设了无机化学、有机化学、物理化学、仪器分析4门双语课程, 实现化学基础课程双语课程不 断线。其中无机化学、有机化学、仪器分析 3 门课程已建成国家双语教学示范课程。在双语教学中采 用国际公认的优秀教材, 将国外先进的教学思想贯穿在教学过程中, 使学生掌握先进专业知识及其 应用, 并在学习学科知识的过程中培养和提高专业外语语言应用能力。另外, 聘请俄罗斯莫斯科大 学、英国卡迪夫大学、英国格拉斯哥大学的外籍教授开设了杂环与药物化学、功能材料及可持续能 源技术和晶体培养与结构解析 3 门小学期国际化课程, 并为每位来华授课教授安排了一位校内教师 作为助手。学生在外籍教授面对面的交流中受益匪浅, 青年教师们也学习了有益的教学方法。

实施海外暑期学校、联合培养等计划, 为开拓学生的国际视野、培养全球化思维能力创造条件。 目前与美国东北大学、英国剑桥大学等十余所国外高校签订联合培养、交换生或暑期学校项目, 每年 有 $10 \%$ 左右的学生参加国际化课程, 接触国际学科前沿, 感受不同文化氛围, 增强国际化交流能力。 


\section{3 加强师资队伍和基层教学组织建设}

\section{1 注重结构建设, 造就理工融合的师资队伍}

一流的师资队伍是一流专业建设的关键。学院加强海外高层次人才引进, 加强具有工程背景的 教师队伍及企业导师队伍建设, 形成了一支以在职教师为主体、以外聘国内外知名专家和企业导师 为两翼的理工结合、校企结合、结构合理的师资队伍。教师中 $50 \%$ 有海外留学经历, $20 \%$ 有工程化经 验。校内教师中, 有中国科学院院士 1 人, 教育部 “长江学者奖励计划” 特聘教授 1 人, “国家杰出 青年基金” 获得者 6 人, “国家优秀青年科学基金” 获得者 5 人, 教育部 “长江学者奖励计划” 青年 学者 1 人, 中组部 “万人计划” 教学名师 1 人, 国家级教学名师 2 人, 国家万人计划科技创新领军人才 3 人, 国家中青年科技创新领军人才 3 人, 全国模范教师 1 人, 教育部跨(新)世纪人才培养计划入选者 12 人, 北京市教学名师 6 人, 北京市优秀教师 1 人, 首批国家级教学团队 1 个, 教育部长江学者和创新 团队发展计划创新团队2 个, 国家自然科学基金委创新研究群体 1 个。

\section{2 强化制度建设, 培养教学科研双赢的师资队伍}

学校及学院建立了岗前培训、工程实践能力培养、教学能力提升、海外进修、岗位考核以及师 德师风建设等制度, 在教学改革、科学研究和技术开发实践中锻炼教师队伍。

组织新入职教师岗前培训, 使之尽快熟悉学校的教学、科研和管理工作。组织教学技能工作坊 研修班、教师外派研修、教学学习分享交流等, 把好课堂教学质量入门关, 提升新教师的课堂执教 能力。组织青年教师工程训练营, 深入行业内大型企业, 参观生产一线、进行校企技术交流, 助力 青年教师将理论与工程实践相结合，提高其工程实践能力和创新意识。

构建了学科交叉、理工融合、应用导向的 “基础研究-应用研究-产学研融合” 的创新育人平台和 科学研究体系。教师在科研实践中不断提升业务能力, 近三年承担纵向和横向科研项目 307 项, 申请 专利 334 件, 授权专利 219 件。把科研优势转化为教学优势, 科研思维进课堂、科研成果进课堂、科 研手段进课堂。以无机化学、有机合成等校级研究性教学示范课程建设为抓手, 营造开放式、探究 式与参与式的学习氛围。学生的科研训练和毕业论文选题与教师科研相结合, 既注重基础研究, 也 注重解决企业实际问题。在导师课题组完成全部实验的过程中, 学生的实践和创新能力得到充分锻 炼。

\section{3 发挥基层教学组织作用, 促进教学质量提升}

基层教学组织以系为单元, 按照课程(群)设立教学团队, 无机化学、分析化学、有机化学、物理 化学、仪器分析、基础化学、结构化学、计算化学、大学化学实验等课程以及应用化学专业课程群 分别由国家、市、校三级教学名师领航, 负责培养计划修订、课程和教材建设、青年教师培养、课 程质量分析及持续改进。各教学团队定期开展教学研讨, 不断提升教学质量和教学研究水平。承担 国家级质量工程建设项目 10余项, 已建成6门国家精品课程和3门双语示范课, 9门在线开放课程, 其 中有 4 门为国家级一流本科课程。出版国家级规划教材等 20 部, 7 部为北京市精品教材。近三年有 2 名 教师在北京市青年教师基本功大赛中获奖, 发表教学研究论文 20 余篇。团队成员获国家级教育教学 成果一等奖1项、二等奖5项。

\section{4 完善专业教学质量保障体系建设}

\section{1 建立校-院-系三级质量监控体系}

由学校教学指导委员会、学院教学指导委员会、系主任及课程群负责人组成三级教学指导组织, 由学校教学巡视组、学院教学巡视组及课程群负责人组成三级质量监控队伍, 以健全的教学监控体 系保障教学质量。

\section{2 建立质量保障管理制度，强化过程管理}

学校制定了相关教学监控管理文件, 如学生评教制度、巡视员听课制度、校领导和中层干部听 课制度、岗位聘任/考核中师德师风及教学质量一票否决制度等。学院也建立了教师试讲、同行听课、 
学生信息员制度等。

在学籍管理、日常教学、教学计划制定修订、教材选用、考试、实习、毕业论文等教学环节实 施中, 均有执行标准并有严格的监控管理体系。教学秩序运行良好, 各类档案文件管理规范。

\section{3 建立教学质量反馈体系的闭环运行机制}

建立校友跟踪反馈和用人单位反馈等外部评价机制, 近三年共选拔人才质量培养观测员 100 余 人。结合学生座谈会、党政联席会、教学指导委员会及教学研讨会等, 内外联动, 对教学质量评价 信息进行综合分析, 持续改进授课质量、修订培养方案, 提升专业人才培养质量。问卷调查显示, 学生对专业教师授课满意度达到 $95.5 \%$, 对专业课程设置的满意度达到 $91.9 \%$ 。

\section{4 毕业生培养质量的跟踪调查结果和外部评价}

近年来毕业生近 $40 \%$ 升入 “ 985 ” 和 “ 211 ” 院校及中科院等攻读硕、博学位; 近 $10 \%$ 出国深造; 就业率 $97.6 \%$ 以上。直接就业的毕业生 $92 \%$ 以上进入国有、合资或民营企业工作, 例如中石油、中石 化、制药集团等大型国企或行业内知名企业以及出入境检验检疫局、环保局等, 并逐渐成为企事业 单位科技创新骨干，就业与专业相关性较好。

跟踪调查结果表明, 毕业生对专业课程设置、授课水平等满意度高, 对专业的喜欢程度高, 认 为所学的知识与技能为自身打下扎实的基础, 能满足岗位及自身发展的要求, 愿意从事本专业相关 工作。用人单位对专业培养质量认可度很高, 认为本专业毕业生人品端正, 具有较强的解决问题能 力, 学习能力强, 沟通能力强, 团队协作意识强。

\section{5 结语}

北京化工大学应用化学专业依托理工同校、理工同强的优势, 探索并实践了培养应用化学创新 人才的途径, 取得了一系列改革成果。未来的化学类人才培养已经呈现出多样化、高端化、综合化、 国际化等时代特征 ${ }^{[4]}$, 我们将以一流本科专业建设为契机, 以立德树人为根本目标, 突出产出导向, 进一步明确人才培养定位, 优化人才培养方案。深入推进课程思政建设, 实现全员全过程全方位育 人。加强教师教学能力培训, 以高阶性、创新性、挑战度为标准, 全面建设金课, 提升教育教学质 量。通过产学研深度合作, 为人才培养拓展更广阔的空间。完善 “优培班” 培养机制, 探索拔尖人 才培养的新途径。深化国际交流与合作, 提升学生的国际交流能力和竞争能力。强化质量保障体系 的作用, 持续提高人才培养质量, 为社会输送理论扎实、实践能力强的理工复合型优秀应用化学人 才。

\section{参 考 文 献}

[1] 吴岩. 中国大学教学, 2017, No. 11, 5.

[2] 杨屹, 陈咏梅, 白守礼, 许家喜, 李蕾, 李保山. 中国大学教学, 2013, No. 7, 15.

[3] 吴岩. 中国大学教学, 2018, No. 12, 4 .

[4] 张树永, 朱亚先. 中国大学教学, 2018, No. 3, 25. 